\title{
BIPLOT ANALYSIS FOR IDENTIFICATION OF SUPERIOR GENOTYPES IN A RECOMBINANT INBRED POPULATION OF WHEAT UNDER RAINFED CONDITIONS
}

\author{
Ashutosh Srivastava $^{1,2 \downarrow}$, Puja Srivastava ${ }^{2}$, R S Sarlach ${ }^{2}$, Mayank Anand Gururani $^{3 *}$ \\ ${ }^{1}$ Department of Botany, Punjab Agricultural University, Ludhiana-141004, India \\ ${ }^{2}$ Department of Plant Breeding \& Genetics, Punjab Agricultural University, Ludhiana-141004, India \\ ${ }^{3}$ Department of Biology, College of Science, United Arab Emirates University, Al Ain, P.O. Box 15551, UAE \\ ${ }^{\dagger}$ Present address: Rani Lakshmi Bai Central Agricultural University, Jhansi-284003, India
}

Received - July 29, 2021; Revision - October 17, 2021; Accepted - October 26, 2021

Available Online - October 30, 2021

DOI: http://dx.doi.org/10.18006/2021.9(5).598.609

\section{KEYWORDS \\ Rainfed \\ Environment \\ GGE Biplot}

Recombinant inbred lines (RILs)

Traditional landraces

Wheat

\begin{abstract}
Physiological traits of wheat genotypes and their trait relation to drought conditions are important to identify the genotype in target environments. Thus, genotype selection should be based on multiple physiological traits in variable environments within the target region. This study was conducted at Punjab Agricultural University during rabi crop seasons 2012-13 and 2013-14 to study the recombinant inbred lines (RILs) of wheat genotypes derived from traditional landraces and modern cultivars (C518/2*PBW343) based on various morpho-physiological traits. A total of 175 RILs were selected for this study based on various tolerance indices. The genotype by trait (GT) biplot analysis was applied to data from seven high-yielding RILs grown under irrigated $\left(\mathrm{E}_{1}\right)$ and rainfed environments $\left(\mathrm{E}_{2}\right)$. The GGE biplot explained $100 \%$ of the total variation for chlorophyll content, grain filling period, peduncle length, water-soluble carbohydrates, grain number, grain yield, and $95.1 \%$ for canopy temperature, $94.9 \%$ for thousand-grain weight. GT-biplots indicated that the relationships among the studied traits were not consistent across environments, but they facilitated visual genotype comparisons and selection in each environment. RIL 84 and RIL108 were close to the average environment (ideal genotype) for all traits studied except chlorophyll content. A well-performing genotype with great environmental stability is called an "ideal genotype. Among all entries, these genotypes performed well. Therefore, among the traits studied, grain filling period, peduncle length, canopy temperature, water soluble carbohydrates, and 1000 grain weight contributed to grain yield under a stress environment. Furthermore, it may be used as a donor material in breeding programs and QTLs mapping.
\end{abstract}

* Corresponding author

E-mail: gururani@uaeu.ac.ae (Mayank Anand Gururani)

Peer review under responsibility of Journal of Experimental Biology and Agricultural Sciences.

Production and Hosting by Horizon Publisher India [HPI] (http://www.horizonpublisherindia.in/).

All rights reserved.
All the articles published by Journal of Experimental Biology and Agricultural Sciences are licensed under a Creative Commons Attribution-NonCommercial 4.0 International License Based on a work at www.jebas.org.

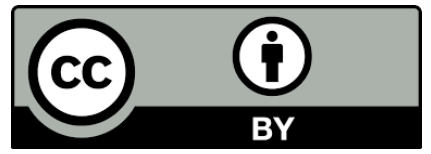




\section{Introduction}

Globally, wheat is the most cultivated crop and is the second most staple cereal crop in India. As per the Ministry of Agriculture, Government of India, $68 \%$ of the total net sown area (142.2 mha) in India was documented as drought-prone (Yaduvanshi et al., 2015). Various researchers have found wheat susceptibility to drought stress, which can result in yield losses of up to $90 \%$ depending on the development stage, genotype, and intensity and length of the dry period (Wang et al., 2019; Gupta et al., 2020; Tian et al., 2020). Drought and water scarcity threaten the agricultural productivity of many developing countries including India to feed their increasing demand and ever-growing population. Drought stress not only affects the plant behavior but also severely affects the metabolism of the plant, physiology, and biochemical responses in plants. These responses include leaf rolling, destruction of the cell membrane, leakage of electrolyte, dysfunction of photosystem II, inactivation of enzyme synthesis which leads to stomatal closure, repression of cell growth and photosynthesis, and activation of photorespiration (Gururani et al., 2015; Alyammahi \& Gururani, 2020; Kappachery et al., 2021). Therefore, physiological and biochemical approaches have great importance in elucidating the complex phenomenon of drought tolerance in plants and understanding the underlying mechanism.

The enhancement of crop productivity under drought conditions requires genotypes with improved physiological traits like better stomatal conductance, higher relative water content, less transpiration utilizing minimum water, cooler canopy, better stem reserve mobilization, and yield stability (Srivastava et al., 2017; Chowdhury et al., 2021) The primary goal of many breeding programs is to identify superior genotypes through considering multiple physiological traits under drought conditions (Yan \& Rajcan, 2002). Physiological aspects of drought tolerance have been shown in a recombinant inbred population of wheat. Association of stomatal density and low canopy temperature with drought stress was found in highyielding cultivars. Furthermore, a correlation has been shown in various traits like peduncle length and water-soluble carbohydrates as well as 1000 grain weight under droughtstressed conditions (Srivastava et al., 2016). It is also reported a trait correlation in chlorophyll fluorescence and chlorophyll content with drought tolerance index which reflects the reproductivity of mapping population of wheat (C306 x HUW206) under rainfed stress conditions (Kumar et al., 2012).

Biplot analysis of a genotype by traits (GT) can help to understand and identify the crop as an integrated system with interconnected components, i.e., multiple breeding objectives. Simultaneously, it helps to unleash the trait profiles (strength and weakness) of the genotypes, which are important for identifying those that are superior in desired traits and hence could be candidates for use as parents in a breeding program (Yan \& Kang, 2002). It also discloses information on the key traits of cultivars besides it assisting in the detection of less significant traits and recognizing those that are suitable for indirect selection of a target characteristic. Furthermore, GGE biplot analysis may be better and more accurate to the graph AMMI1 mega-environment for being more efficient in explaining the sum of squares of GE and G + GE, due to confirmed by its greater predictive accuracy (Bozovic et al., 2020).

Under drought stress conditions, the relationships between yield and physiological traits become the choice of selection and breeding strategies for the breeder. There is also a strong negative relationship or volatile interaction between breeding targets, which makes breeding very difficult and complicated (Jha et al., 2020; Ranjith \& Rao, 2021). Therefore, more attention must be paid to undesirable associations among breeding objectives when performing independent choice, because only selection based on desirable traits or culling for undesired levels of one trait may lead to the loss of useful materials or even render the selection useless (Ranjith \& Rao, 2021). A biplot is a statistical tool to evaluate genotype-by-trait cultivars based on many characteristics and to classify those that are superior in desirable characteristics and consistent yield production in variable environments in the target area. Moreover, it could be used as donor parents in a breeding program or directly released for commercial production. The GT biplot analysis allows a graphical representation of the genetic correlations among traits and their degree and nature of association among the traits (Yan \& Frégeau-Reid, 2008; Bozovic et al., 2020). However, there are pitfalls in interpreting a GT biplot when the biplot does not fully approximate the data. The relationships among physiological traits in bread wheat are frequently influenced by unpredictable conditions in the Mediterranean rain-fed areas. Therefore, the selection of genotypes within the target area should be ground on different traits in an erratic environment. However, little is known about the trait relations and trait profiles of RILs derived from the cross of (C518/2*PBW343) wheat genotypes in rainfed conditions. Both the parents PBW343 (modern cultivar) and C518 (traditional landraces) have contrast characters offering several morpho-physiological traits (Table.1). PBW343 is a modern cultivar and known for high-yielding variety but input responsive in drought conditions. Although C518 is a long-height old cultivar and can mobilize stalk reserve in stressful conditions because of larger peduncles and low input (Bala et al., 2010). The present study was undertaken to assess the performance of promising RILs under two different water regimes and to identify superior genotypes better adapted to rainfed conditions by examining different physiological traits. 
Table 1 Characteristic traits of parental lines

\begin{tabular}{|c|c|c|c|c|c|c|c|c|}
\hline \multirow{2}{*}{ S. No. } & \multirow{2}{*}{ Traits } & \multicolumn{2}{|c|}{ Parents } & \multicolumn{5}{|c|}{ RILs } \\
\hline & & PBW343 & C518 & 32 & 47 & 80 & 84 & 108 \\
\hline 1 & Plant Height & $\begin{array}{l}\text { Medium (95- } \\
100 \mathrm{~cm})\end{array}$ & $\begin{array}{l}\text { Tall }(125- \\
130 \mathrm{~cm})\end{array}$ & $\begin{array}{c}\text { Medium- } \\
\text { tall }(104- \\
108 \mathrm{~cm})\end{array}$ & $\begin{array}{l}\text { Tall (114- } \\
118 \mathrm{~cm})\end{array}$ & $\begin{array}{l}\text { Small }(84- \\
88 \mathrm{~cm})\end{array}$ & $\begin{array}{c}\text { Medium- } \\
\text { tall }(104- \\
108 \mathrm{~cm})\end{array}$ & $\begin{array}{l}\text { Medium- } \\
\text { tall }(106- \\
110 \mathrm{~cm})\end{array}$ \\
\hline 2 & Peduncle Length & Medium & Long & Medium & Long & small & Medium & Medium \\
\hline 3 & $\begin{array}{c}\text { Stomatal } \\
\text { Conductance }\end{array}$ & High & Low & $\begin{array}{c}\text { Moderate } \\
\text { high }\end{array}$ & $\begin{array}{l}\text { Moderate } \\
\text { Low }\end{array}$ & High & $\begin{array}{c}\text { Moderate } \\
\text { high }\end{array}$ & $\begin{array}{c}\text { Moderate } \\
\text { high }\end{array}$ \\
\hline 4 & $\begin{array}{l}\text { Grain Filling } \\
\text { Period }\end{array}$ & Medium & Longer & Longer & Medium & Medium & Longer & Longer \\
\hline 5 & $\begin{array}{c}\text { Chlorophyll } \\
\text { Content }\end{array}$ & High & Low & Medium & Low & Medium & High & High \\
\hline 6 & $\begin{array}{l}\text { Peduncle and } \\
\text { leaves colour }\end{array}$ & Green & $\begin{array}{l}\text { Green } \\
\text { turn } \\
\text { golden } \\
\text { color }\end{array}$ & $\begin{array}{l}\text { Green } \\
\text { yellow }\end{array}$ & $\begin{array}{l}\text { Green } \\
\text { yellow }\end{array}$ & Green & $\begin{array}{l}\text { Green turn } \\
\text { golden } \\
\text { color }\end{array}$ & $\begin{array}{l}\text { Green turn } \\
\text { golden } \\
\text { color }\end{array}$ \\
\hline 7 & $\begin{array}{l}\text { Agronomic } \\
\text { condition }\end{array}$ & $\begin{array}{c}\text { Input } \\
\text { responsive }\end{array}$ & Low input & $\begin{array}{c}\text { Medium } \\
\text { input }\end{array}$ & Low input & $\begin{array}{c}\text { Input } \\
\text { responsive }\end{array}$ & Low input & Low input \\
\hline
\end{tabular}

\section{Materials and Methods}

\subsection{Experimental design and data collection}

The paired experiments (rain-fed and irrigated conditions) were conducted at Punjab Agricultural University, Ludhiana, India, during the cropping seasons 2012-13 and 2013-14. The experimental trial was conducted in a randomized block design with two replications, with a plot size of $1 \mathrm{~m}$ per row and a rowto-row spacing of $20 \mathrm{~cm}$. Recombinant inbred lines (RIL) population (700 lines including parents) were procured from Wheat Section, Punjab Agricultural University, Ludhiana. In the first-year experiment, a set of 700 RILs including parents (PBW 343 and C518) were evaluated for morpho-physiological traits viz., canopy temperature, chlorophyll content, water-soluble carbohydrates, stem research mobilization, grain filling period, and from this a small subset of 175 RILs reconstituted for further evaluation based on yield percent reduction. Later the subsequent year, a total of 175 RILs derived from drought tolerance and moderately susceptible wheat cultivars (C518 and PBW343 respectively) along with parents were evaluated in this study (Figure 1). Thereafter, based on the tolerance index, seven promising genotypes viz., RIL 32, RIL 47, RIL 80, RIL 84, RIL 108, PBW343, and C518 were selected for biplot analysis. Normal recommended agronomic practices were followed for growing wheat crops. Meteorological data weekly were recorded from the agrometeorological station, Punjab Agricultural University, Ludhiana, presented in Figure 2. The traits recorded for each genotype under both rain-fed and irrigated conditions during cropping seasons were: peduncle length (PL), chlorophyll content index (CCI), grain filling period (GFP), water-soluble carbohydrates (WSC), Number of grains per spike (GN) and grain yield (GY) as described earlier (Kumar, 2015).

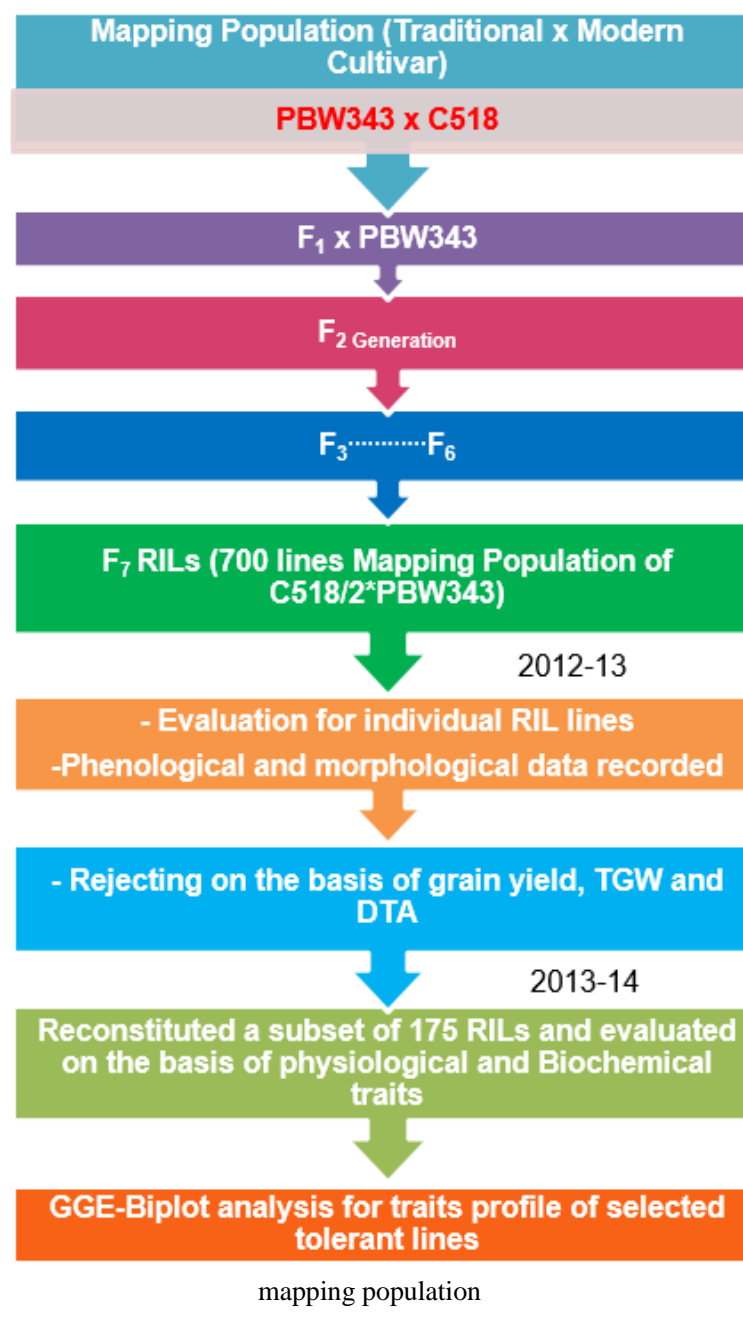

Journal of Experimental Biology and Agricultural Sciences http://www.jebas.org 


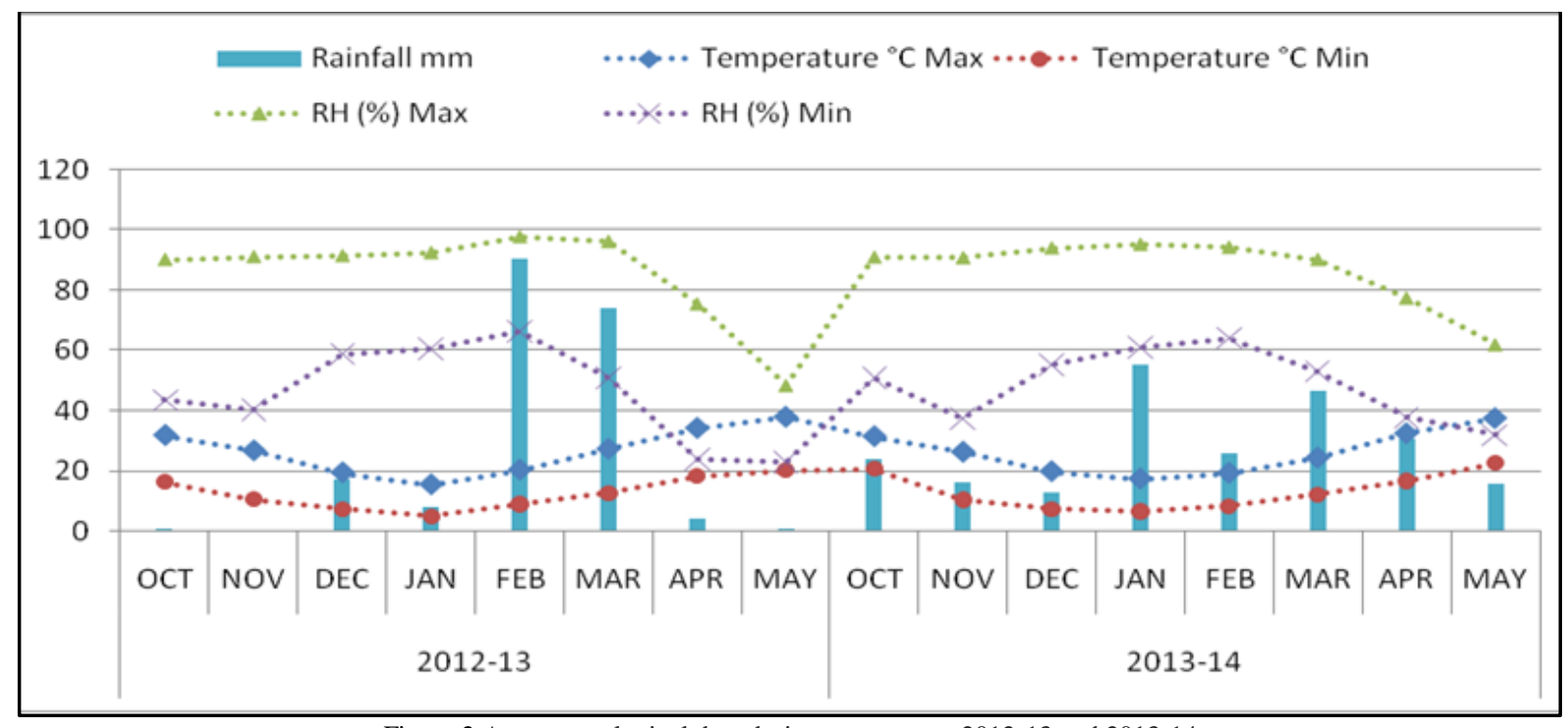

Figure 2 Agrometerological data during crop season 2012-13 and 2013-14

\subsection{Statistical Analysis}

The GGE biplot software (version 2.2.210) was employed to display the genotype-by-trait relations two-way data in a biplot for each environment. A vector is created from the biplot origin to the relevant trait markers in the GT biplot to show the relationship between the characteristics. The correlation coefficient of any two traits is approximated by the cosine of the angle between their vectors. Acute angles show positive correlations, obtuse angles suggest negative correlations, and right angles indicate no association. A short vector may mean that the trait is not linked to any other trait (Yan, 2001).

\section{Results and Discussion}

3.1 Interrelationship between genotypes and environments (irrigated $E_{1}$ and rainfed $E_{2}$ )

Environment vectors are the lines that link the biplot origin to the markers. The correlation coefficient between two conditions is proportional to the angle between their vectors (Yan, 2002). Broad obtuse angle, or strong negative associations among the environment, indicated a strong genotype-by-environment relationship (Katuuramu et al., 2020). Concerning genotype discrimination, the distance between two environments tests their dissimilarity. According to GGE analysis, ideal cultivars are those that should have large PC1 scores (high mean value) and small (absolute) PC2 scores (high stability). The GGE biplot explained $100 \%$ of the total variation for chlorophyll content, grain filling period, peduncle length, water soluble carbohydrates, grain number, grain yield, and $95.1 \%$ for canopy temperature, $94.9 \%$ for 1000 grain weight (Figure 3). This relatively high percentage variation reflects the accuracy of interrelationships among the measured traits. Most angles between their vectors are acute. The genotype's vector length indicates the extent of its influence (positive or negative) on a specific phenotype (Yan \& Tinker, 2005). Thus, the majority of RILs were highly correlated with parent C518 except for chlorophyll content and grain yield (Figure 3a-h). PBW343 showed high chlorophyll in $E_{1}$ and $E_{2}$ environments as their vector lay between $\mathrm{E}_{1}$ and $\mathrm{E}_{2}$ environments. The interspace between a genotype and the biplot origin is a special indicator of the genotype's difference from an ordinary genotype (Yan \& Frégeau-Reid, 2008). Genotypes having a long distance from the biplot origin exhibits disproportionately high levels of one or more characteristics. These genotypes are not always superior, but they do act as parents for specific traits. Thus, RIL 80 had the longest distance from biplot origin followed by RIL 84 and RIL108. However, RIL 84 had a negative interaction with $E_{2}$ and RIL 80 had a positive interaction with $E_{1}$. Genotypes in the biplot's centre show no interaction, implying that their mean value is stable across two environments $\mathrm{E}_{1}$ and $\mathrm{E}_{2}$. Therefore, RIL 47, RIL 32, RIL 108, and C518 are located in this category, and it can be considered as stable performance (Figure 3a). In the case of grain filling period (Figure 3b), C518 showed the maximum grain filling period under both $E_{1}$ and $E_{2}$ but positive interaction with $E_{2}$ as the length of the vector is more and their angle is less than $90^{\circ}$ and hence specific adaptability with $\mathrm{E}_{2}$. However, PBW343 had a negative interaction with $\mathrm{E}_{2}$. Moreover, among the tested RIL, the RIL108, RIL 47, and RIL 80 were found an inverse relationship with C518 as their vector showed an obtuse angle, i.e., it had a minimum grain filling period than C518. While RIL 32 and RIL 84 had a close relationship with C518 by their acute angle, i.e., it showed at par the mean value of C518. For peduncle length (Figure 3c), C518 had maximum peduncle length over $E_{1}$ and $E_{2}$. However, PBW showed an inverse relationship with C518 as their 
obtuse angle, i.e., minimum peduncle length in comparison to C518. Likewise, RIL 80 and RIL 30 were also found an inverse relationship with C518 but a close relationship with PBW343 by their vectors showed an acute angle. Moreover, RIL 108, RIL 84, and RIL 47 showed a close relationship with C518 as their vectors showed acute angle, but RIL 47 showed nearest to biplot origin, i.e., their mean value is stable under both $\mathrm{E}_{1}$ and $\mathrm{E}_{2}$ environments.

For canopy temperature at anthesis and post-anthesis (Figure 3d), PBW343 showed a close relationship with C518 under $E_{1}$ and $E_{2}$ as their vectors showed acute angle but PBW343 and RIL 80 showed nearest to biplot origin as it has a stable mean value under $\mathrm{E}_{1}$ and $\mathrm{E}_{2}$ environments. Likewise, RIL 108 showed an acute angle between them and had a close relationship with $E_{1}$ and $E_{2}$ environments, i.e., they have higher temperatures in $\mathrm{E}_{1}$ and $\mathrm{E}_{2}$. However, RIL 84 and RIL 47 showed an inverse relationship with $E_{1}$ and $E_{2}$ as their vectors showed an obtuse angle between them, i.e., they have minimum temperature under both $E_{1}$ and $E_{2}$ environments. Similarly, for mobilized water-soluble carbohydrates (Figure 3e), C518 had maximum mobilized watersoluble carbohydrates under both $\mathrm{E}_{1}$ and $\mathrm{E}_{2}$ environments as their vectors lied between $\mathrm{E} 1$ and $\mathrm{E}_{2}$ and had closed to environment vector. Whereas PBW343 and RIL 108 showed a negative relationship with C518 as their vector showed an obtuse angle $\left(>90^{\circ}\right)$ i.e., they have minimum water-soluble carbohydrates in contrast to C518. However, RIL80, RIL 47, RIL 32, and RIL 84 had a close relationship between them as their vectors showed an acute angle, but RIL 80 showed closer to biplot origin, i.e., they have stable values at par to $\mathrm{C} 518$ under $\mathrm{E}_{1}$ and $\mathrm{E}_{2}$ environments.

Like in the previous, C518 showed stable performance, i.e., maximum 1000 grain weight (grain weight in normal and defoliation) under both $\mathrm{E}_{1}$ and $\mathrm{E}_{2}$ environments as their vector lied between them and closed to biplot origin. Whereas PBW343 showed an inverse relationship with $\mathrm{C} 518$ as well as $\mathrm{E}_{1}$ and $\mathrm{E}_{2}$ environments as their vectors showed an obtuse angle between them. RIL 108 and RIL 84 had a closer relationship with $\mathrm{E}_{1}$ and E2, but RIL 47 and RIL 84 showed stable performance under both environments as their position was closed to the biplot origin (Figure 3f). Biplot analysis for the number of grains per spike showed an inverse relationship between C518 and PBW343 (Figure 3g) However, RIL 80 showed a maximum number of grains per spike as their vector lied approximately middle position between $E_{1}$ and $\mathrm{E}_{2}$ environments followed by C518 which showed a close relationship between them while PBW343 had an inverse relationship with $\mathrm{E}_{2}$. RIL 32, RIL 108, and RIL 84 have a close relationship with PBW343 as their vectors are shown by an acute angle. Similarly, for grain yield, C518 and PBW343 showed an inverse relationship between them as their vectors showed an obtuse angle $\left(>90^{\circ}\right)$ but the performance of C518 showed higher in comparison to PBW343 as their vector lines on a positive axis.
However, RIL 32, RIL 47, RIL 108, and RIL 80 showed maximum grain yield under both $\mathrm{E}_{1}$ and $\mathrm{E}_{2}$ environments as their vectors closed to the environmental vector, but RIL 32 and RIL 47 had stable performance under both $\mathrm{E}_{1}$ and $\mathrm{E}_{2}$ as they showed closet position form biplotorigin (Figure $3 \mathrm{~h}$ ). Similar studies have also reported the effectiveness of GGE plot in identifying superior genotypes under different environments (Bányai et. al., 2020; Bishwas et. al., 2021)

\subsection{Which-won-where pattern of biplot analysis}

Yan et al. (2000) reported the depiction of the "which-won-where" pattern of biplot analysis is essential for investigating genotype interactions in diverse contexts. To identify the stable genotypes, polygon view analysis of bioplot is the best tool to visualize the relationship between genotypes and environments (Yan \& Kang, 2002). The farthest genotypes are joined to create a polygon to form the Which-Won-Where graph. Following that, perpendicular lines are drawn from the biplot's origin to each of the polygon's sides, dividing the biplot into multiple sectors, each with a single genotype at the polygon's vertex. These lines are known as lines of equality (Yan, 2001). In one or more conditions, the genotypes at the polygon's vertices are the best or the worst. Within the environments, the genotype near the polygon's vertex has the highest performance (Yan \& Tinker, 2005). Which-won-where biplots for chlorophyll content, canopy temperature, grain filling period, water-soluble carbohydrates, peduncle length, 1000 grain weight, number of grains per spike, and grain yield over two environments $E_{1}$ and $E_{2}$ are presented in Figure 3i-p respectively. Polygon for chlorophyll content showed vertex genotype PBW343, RIL 80, RIL 108, and RIL 84 (Figure 3i). While PBW343 showed higher chlorophyll content under both $\mathrm{E}_{1}$ and $\mathrm{E}_{2}$ environments followed by RIL 47. The vertex RIL 80, RIL 108, and RIL 84 showed minimum chlorophyll content as they showed no environment in their sector. In sector 2, C518 showed stable mean values under $E_{1}$ and $E_{2}$ environments as their position showed close to biplot origin. Similarly, canopy temperature at anthesis and post-anthesis showed vertex genotype C518, RIL 108, RIL 32, RIL 84, and RIL 47. C518 showed higher canopy temperature at anthesis in $\mathrm{E}_{1}$ and $\mathrm{E}_{2}$ followed by PBW343. RIL 108 at the vertex in the sector showed higher canopy temperature at post-anthesis in $E_{1}$ (irrigated) and $E_{2}$ (rainfed). However, RIL 80 showed a stable mean value i.e., low canopy temperature at anthesis and postanthesis in $E_{1}$ and $E_{2}$ environments (Figure 31). Polygon view analysis for the grain filling period showed vertex genotypes C518 RIL 47, PBW343, RIL 80, and RIL 84. C518 showed the maximum grain filling periods as they were farthest from biplot origin under $E_{1}$ and $E_{2}$ followed by RIL 32 . However, PBW343, RIL 47, RIL 80, and RIL 84 showed the minimum grain filling period in comparison to $\mathrm{C} 518$ as there were no environments in their sector (Figure 3j). Similarly, for mobilized water-soluble 
carbohydrates (Figure $3 \mathrm{~m}$ ), polygon showed vertex genotypes C518, RIL 84, RIL 47 PBW343 and RIL 32. Parent C518 showed maximum water-soluble carbohydrates under both $\mathrm{E}_{1}$ and $\mathrm{E}_{2}$ as their position showed farthest to biplot origin in $E_{1}$ and $E_{2}$ environments followed by PBW343 but not stable in mean value as their sector does not fall in $\mathrm{E}_{1}$ and $\mathrm{E}_{2}$. Moreover, RIL 47, RIL 32, and RIL 84 showed less water-soluble carbohydrates in comparison to $\mathrm{C} 518$, but they showed stable values in $\mathrm{E}_{1}$ and $\mathrm{E}_{2}$ as their position showed close to biplot origin on PC2. For peduncle length, the which-won-where pattern of biplot analysis showed vertex genotypes C518, RIL 84, RIL 80, PBW343, and RIL 108. Parent C518 showed maximum peduncle length under $E_{1}$ and $E_{2}$ followed by RIL 108 and RIL 84 as their sectors fall in a certain environment. However, genotypes PBW343 and 80 showed minimum peduncle length in comparison to C518 as they showed an inverse relationship (Figure 3k). Polygon view for 1000 grain weight showed vertex genotypes RIL 32, RIL 80, PBW343, and RIL 108. RIL 82 showed the maximum 1000 grain weight (grain weight in normal condition) under $\mathrm{E}_{1}$ followed by C518 (Figure 3n). While RIL 108 showed a maximum 1000 grain weight (grain weight defoliation) under E2 followed by RIL 84 i.e., at par value of C518. However, PBW343 showed a minimum 1000 grain weight (under normal and defoliation) under $E_{1}$ and $E_{2}$ as their sectors showed inverse form under certain environments. Similarly, for grain number (Figure 3o), vertex genotypes RIL 80, RIL 47, PBW343, RIL 32, and C518. While RIL 80 showed the maximum grain number under $E_{1}$ and $E_{2}$ as their position showed farthest to biplot origin in a certain environment followed by C518 and RIL 47. Moreover, PBW343 showed unstable in mean value under $E_{1}$ and $E_{2}$ environment as their position showed farthest to biplot origin on PC2. Likewise, in previous polygon view for grain yield showed vertex genotypes RIL 108, RIL 84, C518, PBW343, and RIL 80. RIL 108 showed maximum grain yield under $\mathrm{E}_{1}$ and $E_{2}$ environment followed by RIL 32 and RIL 47 as their sector fell in $E_{2}$ environment and showed stable value with high performance as their position closed to biplot origin. However, parents C518 and PBW343 showed an inverse relationship as they fell in different sectors and showed the opposite in certain environments (Figure 3p).

\subsection{Mean performance and stability of genotypes}

The selected RILs and their parents based on their mean values of different traits and stability performance were shown in Figure 3q$\mathrm{x}$. The passing line through the biplot is called the average environment coordinate (AEC), which is determined in all environments by the average PC1 and PC2 values. The AEC abscissa is the single arrowhead line. The AEC abscissa runs across the biplot root and the average environmental marker, pointing upwards the higher average values. The perpendicular lines to the AEC passing through the biplot origin are referred to as the AEC ordinate. These ordinates are represented by a pair of arrowed lines in Figure 3q-x. The longer a cultivar's projection is, the less stable it is. In addition, the estimates of their markers of the AEC abscissa are used to estimate the average significance of genotypes for various traits (Kaya et. al., 2006; Mwiinga et al., 2020). However, the stable genotypes have a shorter vector from the AEC, and yielded genotypes have the most distance on the right side of the biplot from the confluence point of AEC and double arrow lines. Accordingly, the chlorophyll content of PBW343 showed a maximum value with stability under $E_{1}$ and $E_{2}$ environments as their position showed farthest to biplot origin on AEC followed by RIL 47, RIL 84, C518, RIL 32, RIL 80, and RIL 108. However, C518 and RIL 32 showed more stability than RIL 80 and RIL 84 as their shorter length of projection (Figure 3q). Similarly, for canopy temperature at anthesis and grain filling (Figure 3t), C518 showed higher canopy temperature at anthesis under $E_{1}$ and $E_{2}$ environment followed by RIL 108 PBW343 and RIL 80. While RIL 80 and PBW343 showed more stability than other entries as their project line, close AEC ordinate and RIL 108 showed higher canopy temperature in $\mathrm{E}_{1}$ (CT at grain filling under irrigated) and $\mathrm{E}_{2}$ (CT at grain filling under rainfed) environments as their greater projection in $\mathrm{E}_{1}$ and $\mathrm{E}_{2}$. Moreover, RIL 84 showed the lowest canopy temperature while RIL 32 and RIL 47 exhibited the lowest stability under certain environments. C518 showed the maximum grain filling period followed by RIL 32 and RIL 84 . While PBW343 showed the minimum grain filling periods and their mean values at par with RIL47 and RIL 108 (Figure 3r). Similarly, C518 showed higher mobilization of water-soluble carbohydrates under $\mathrm{E}_{1}$ and $\mathrm{E}_{2}$ environments followed by RIL 84 and RIL 80. RIL 84, RIL 80, RIL 32, and RIL 47 showed higher mobilization of water-soluble carbohydrates in the $\mathrm{E}_{2}$ environment. Moreover, PBW343 showed relatively unstable under $E_{1}$ and $E_{2}$ environments (Figure 3u). For peduncle length, C518 showed maximum length with more stability under $\mathrm{E}_{1}$ and $\mathrm{E}_{2}$ environments followed by RIL 108, RIL 84and RIL 47 but relatively less stable in mean values. PBW showed minimum peduncle length with stability and their mean values at par with RIL 80 (Figure 3s).

RIL 32 showed a maximum 1000 grain weight (grain weight in normal and defoliation) under $\mathrm{E}_{1}$ followed by C518, RIL 108, and RIL 84. While C518 showed stability under both environments for grain weight (Figure 3v). Similarly, for grain number, RIL 80 showed the maximum grain number with stability under $E_{1}$ and $E_{2}$ environment followed by C518 and RIL 47. PBW343 showed higher instability in grain number under $\mathrm{E}_{1}$ and $\mathrm{E}_{2}$ environments followed by RIL 47 (Figure 3w). Mean values of grain yield showed maximum yield with more stability for RIL 108 and RIL 84 under $E_{1}$ and $E_{2}$ environments followed by RIL 80, RIL 32, and RIL 47. While C518 and PBW343 showed minimum yield relative to other tolerance RILs as their positive lied inverse to certain environments (Figure 3x). 


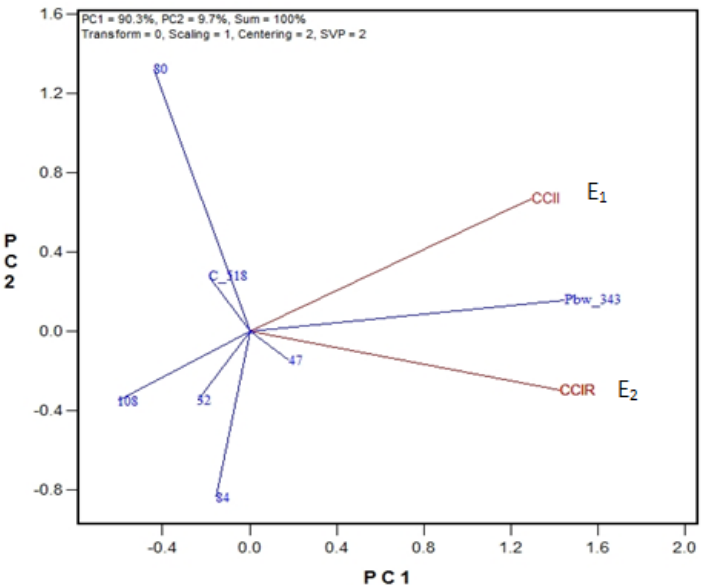

(a) Chlorophyll content index (CCI)

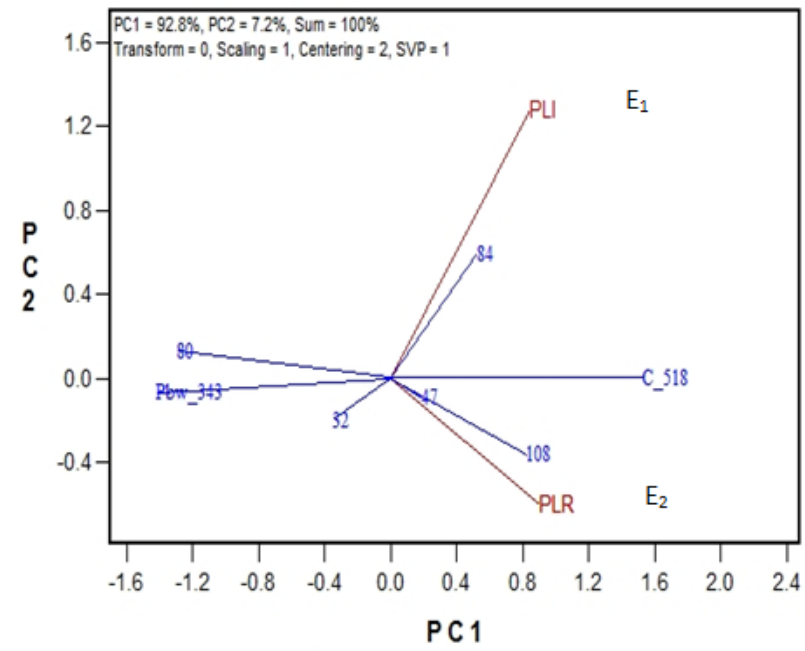

(c) Peduncle length (PL)

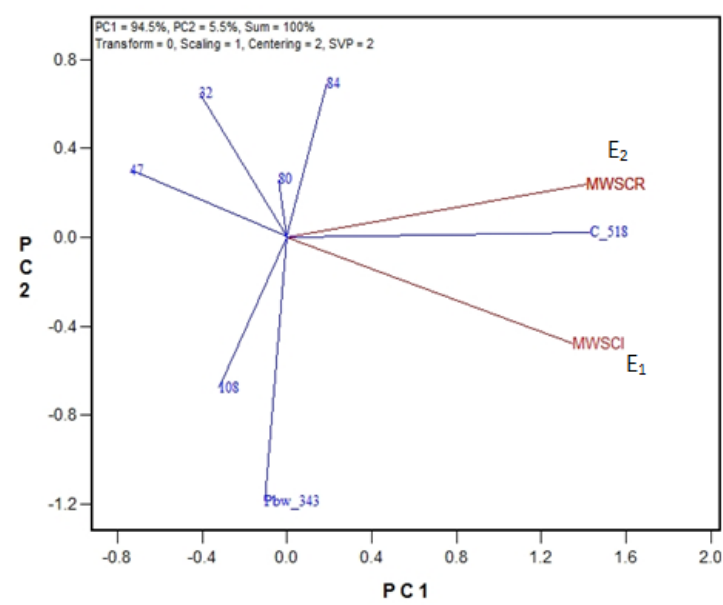

(e) Mobilized water soluble carbohydrates (MWSC)

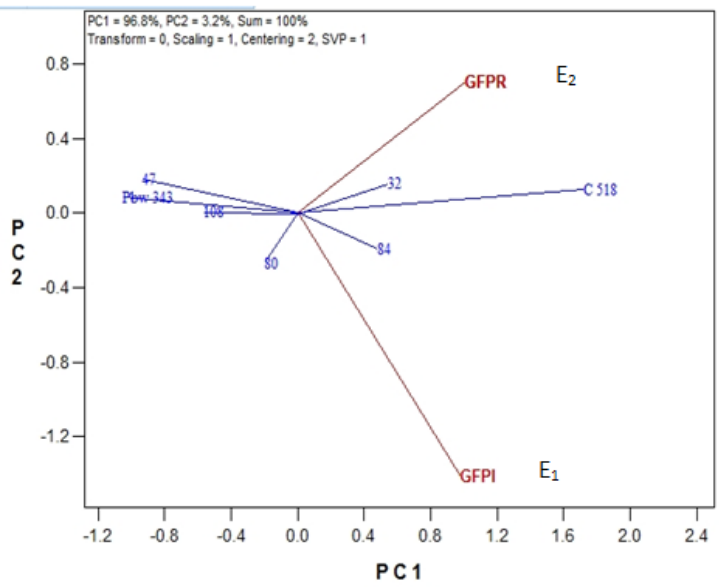

(b) Grain filling period (GFP)

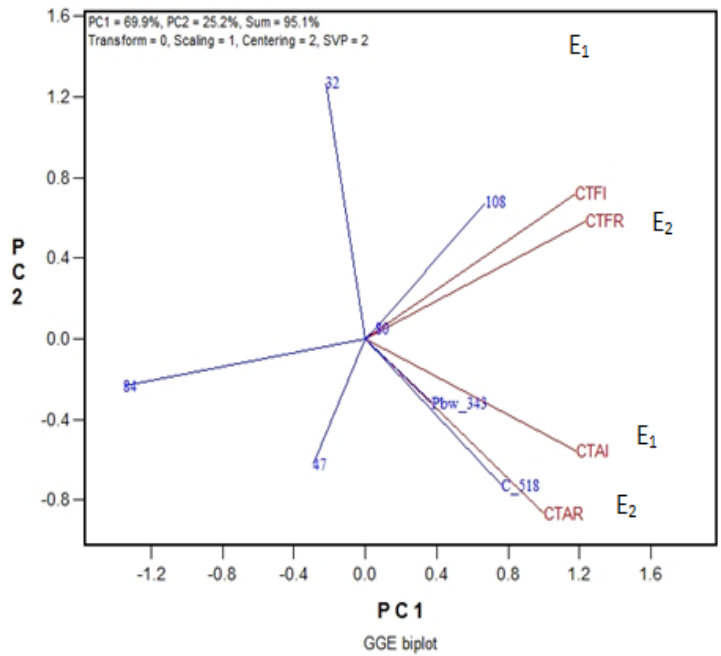

(d) Canopy temperature at anthesis and grain filling

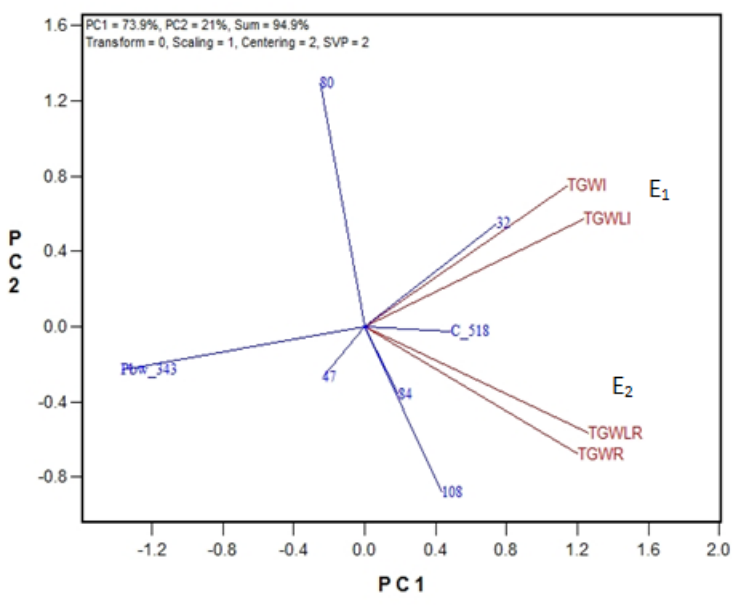

(f) 1000 grain weight under normal and defoliation (TGW \& TGWL)

\section{Contd...Figure 3}

Journal of Experimental Biology and Agricultural Sciences http://www.jebas.org 


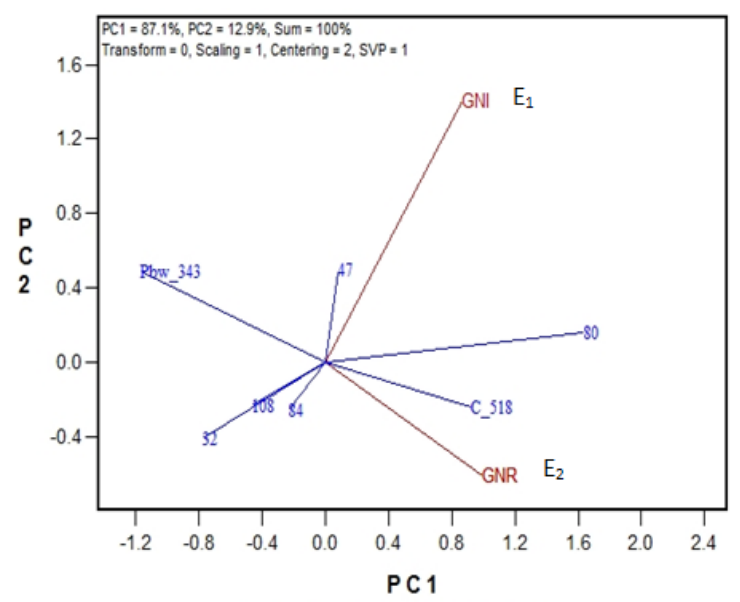

(g) Grain number (GN)

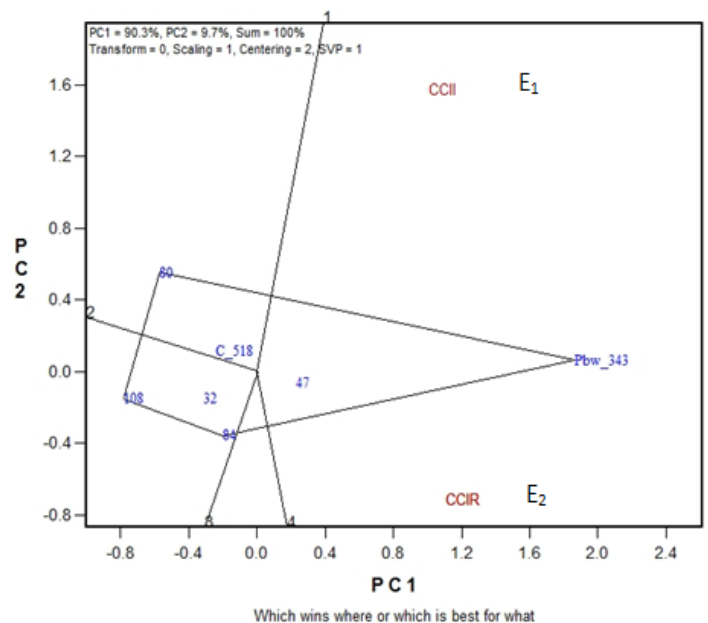

(i) Chlorophyll content index (CCI)

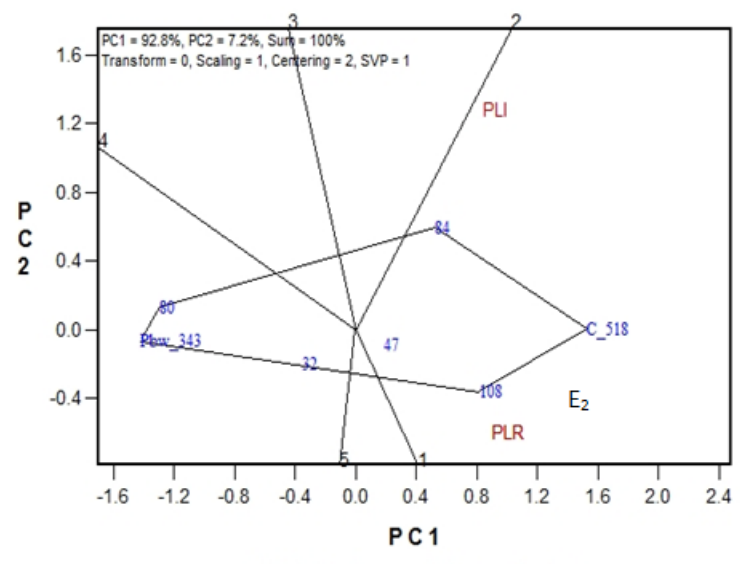

Which wins where or which is best for what

(k) Peduncle length (PL)

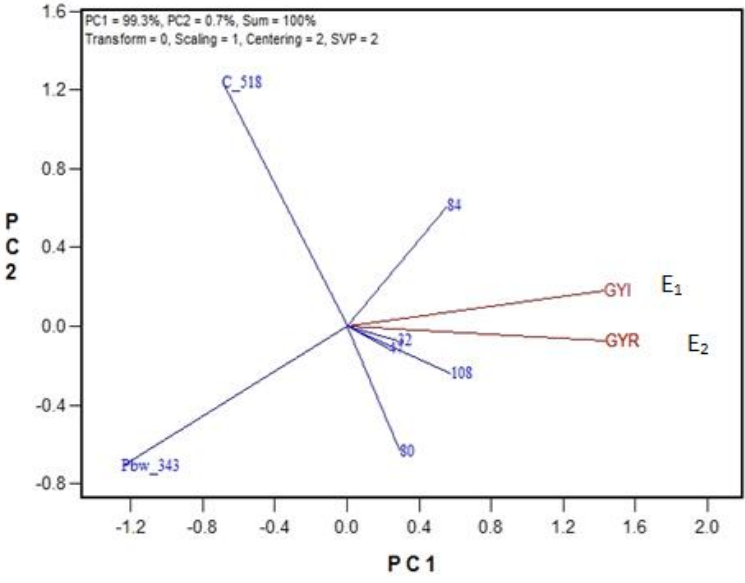

(h) Grain yield (GY)

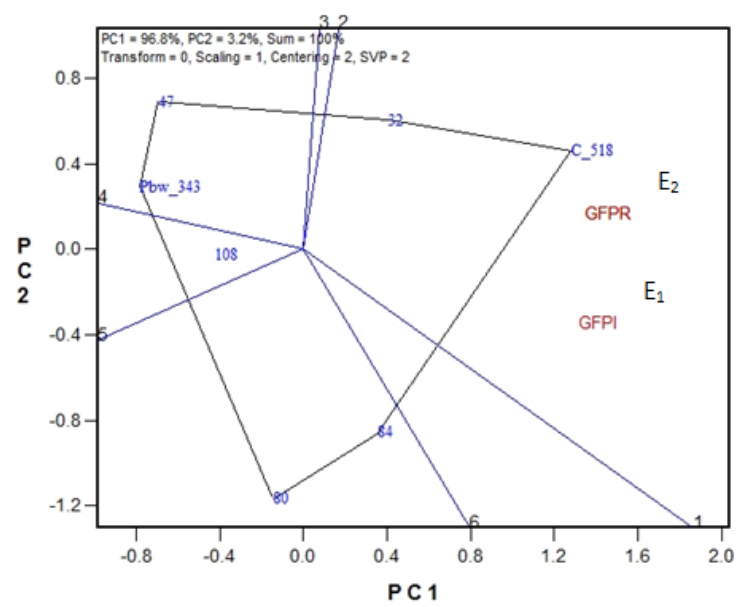

Which wins where or which is best for what

(j) Grain filling period (GFP)

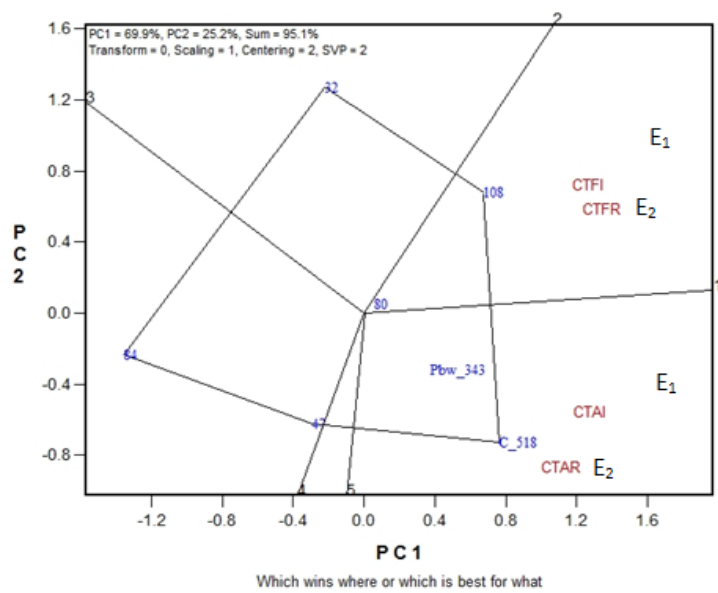

(1) Canopy temperature at anthesis and grain filling

\section{Contd...Figure 3}

Journal of Experimental Biology and Agricultural Sciences http://www.jebas.org 


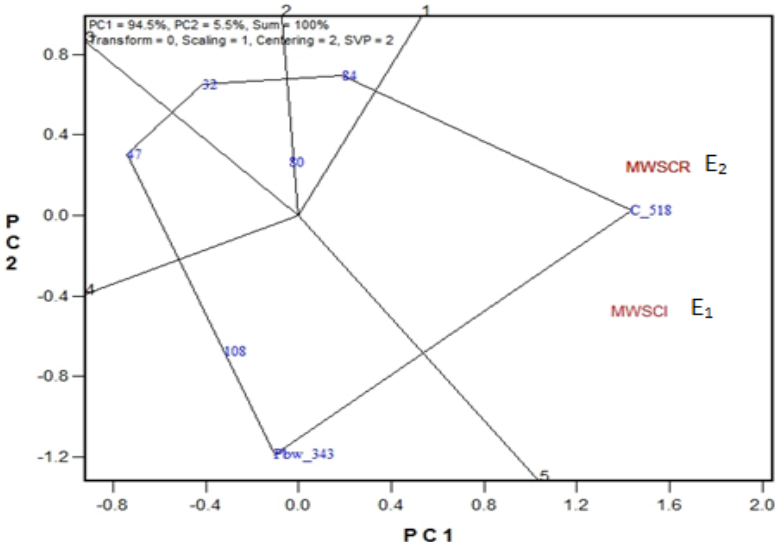

Which wins where or which is best for what

(m) Mobilized water soluble carbohydrates (MWSC)

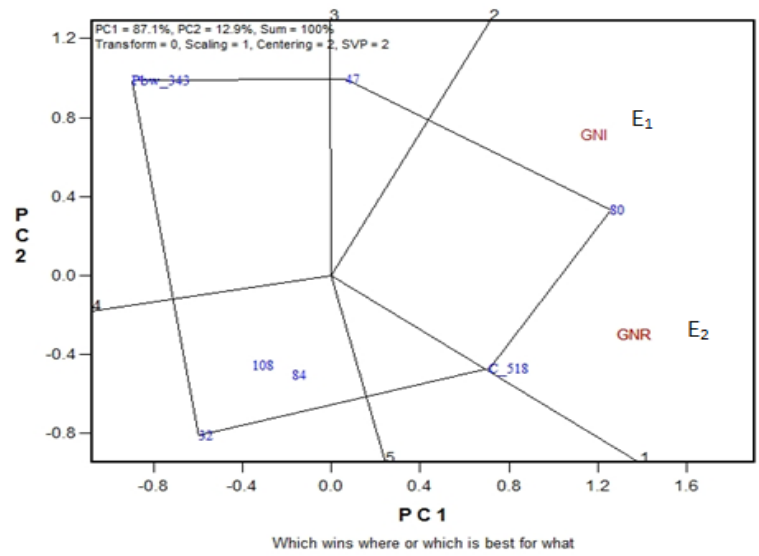

(o) Grain number (GN)

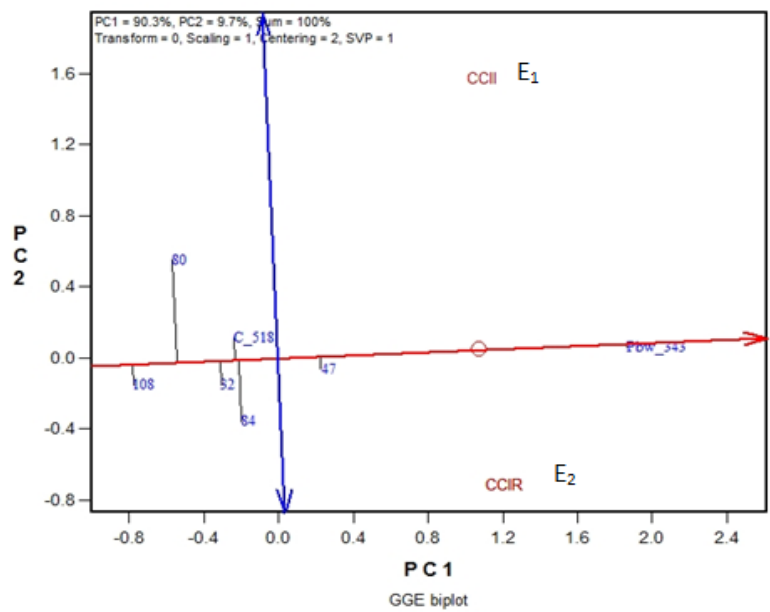

(q) Chlorophyll content index (CCI)

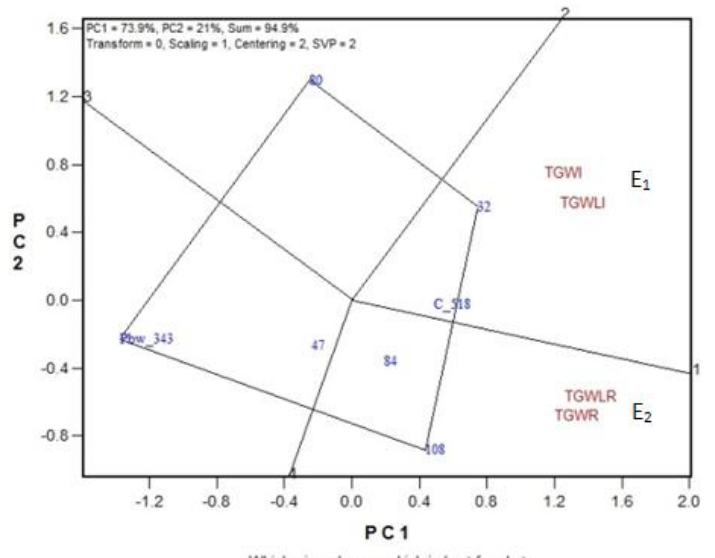

Which wins where or which is best for what

(n) 1000 grain weight under normal and defoliation (TGW \&TGWL)

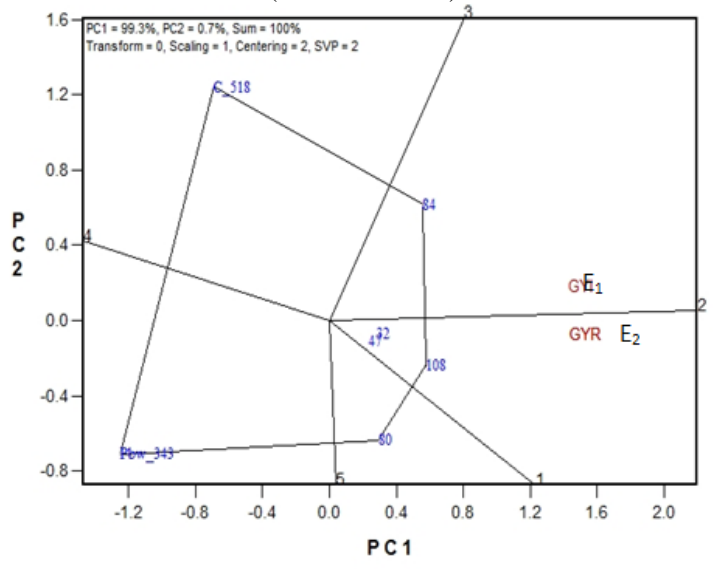

Which wins where or which is best for what

(p) Grain yield (GY)

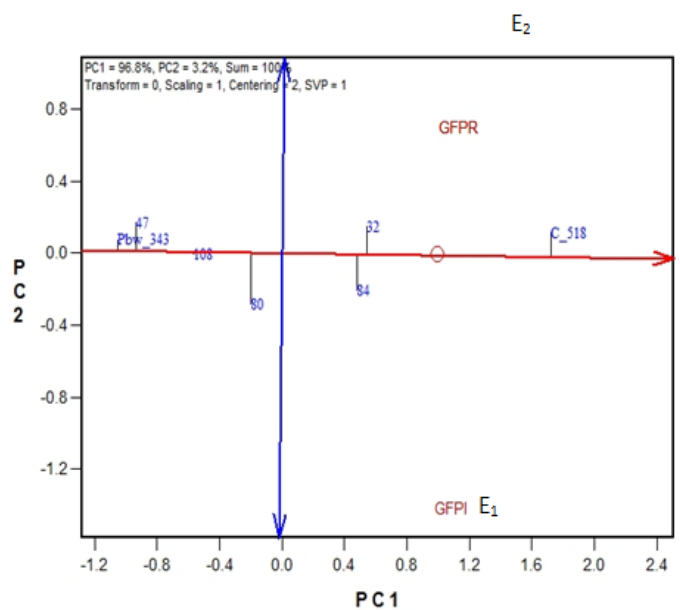

(r) Grain filling period (GFP)

\section{Contd...Figure 3}

Journal of Experimental Biology and Agricultural Sciences http://www.jebas.org 


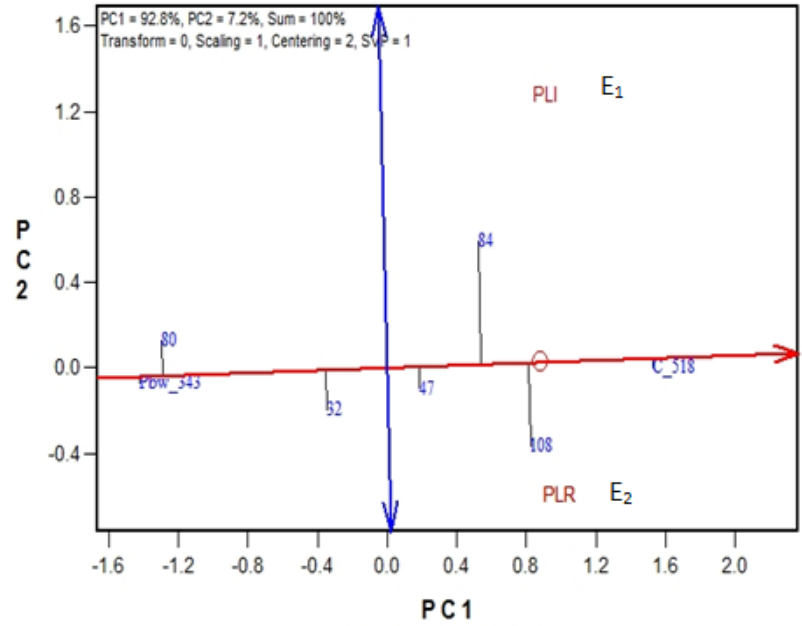

(s) Peduncle length (PL)

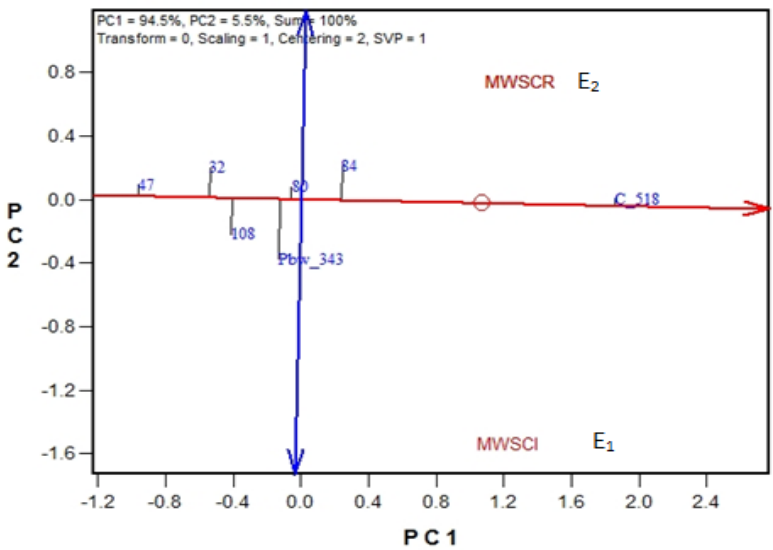

(u) Mobilized water soluble carbohydrates (MWSC)

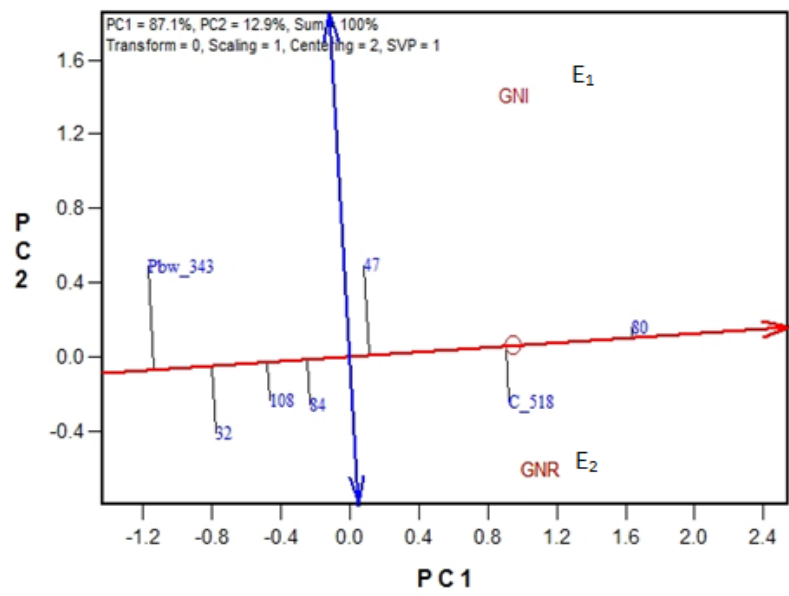

(w) Grain number (GN)

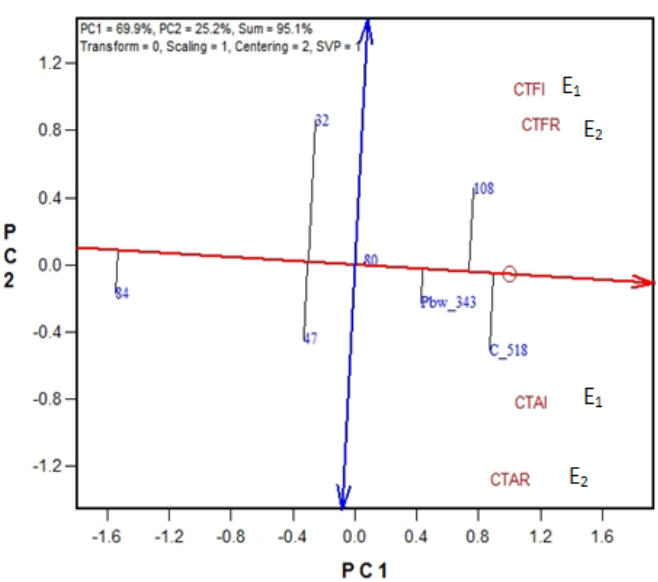

(t) Canopy temperature at anthesis and grain filling

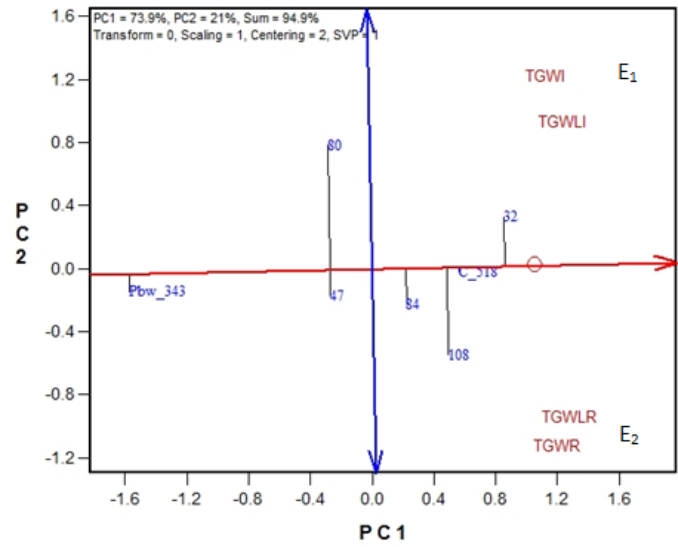

(v) 1000 grain weight under normal and defoliation (TGW \&TGWL)

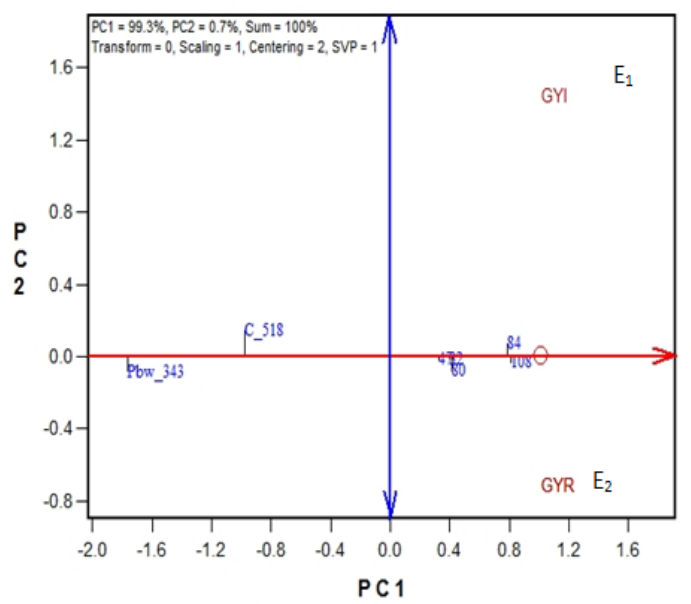

(x) Grain yield (GY)

Figure 3 GGE biplots analysis for chlorophyll content index, grain filling period, peduncle length, canopy temperature at anthesis and grain filling, mobilized water soluble carbohydrates, 1000 grain weight under normal and defoliation, grains number and grain yield; a-h Relation among the genotypes and environments; i-p Which-won-where analysis of the genotypes; q-x Mean versus stability of the genotypes

Journal of Experimental Biology and Agricultural Sciences http://www.jebas.org 
The graphical representation of the GT biplot showed that the genotype performances concerning different Agro-physiological traits in two different environments. The relationship between traits and genotypes varied by the environment, indicating genotype-by-traits-by-environment interaction. Further association between genotypes and traits differed under rainfed as well as irrigated environments. So far, these interactions complex the understanding of genotype-by-traits analysis in a breeding program. GT biplot graphical representation helps in finding stable and ideal genotypes associated with important traits. To find the most stable high-yielding genotypes and their association with physiological traits, we applied GGE biplot analysis in a mapping population of wheat and results showed clear interrelationships among traits, genotypes, and environments other than commonly used methods such as path coefficient analysis and Pearson's correlation analysis. Similarly, the GT biplots were found to be a more accurate method for graphically depict of genotype-by-trait data and disclosing trait interrelationships (Peterson et. al., 2005; Egesi et. al., 2007; Fernández-Aparicio et. al., 2009).

\section{Conclusion}

The above studies stated that RIL 84 and RIL 108 were projected close to the average environment (ideal genotype) for all traits studied except chlorophyll content. Vector projected close to the average environment is considered as ideal genotypes as it has higher stability across the environments. Therefore, among the traits studied, grain filling period, peduncle length, canopy temperature, water-soluble carbohydrates, and 1000 grain weight contributed to grain yield under stress environment. These identified RILs may serve as a donor in further breeding programmes for the development of drought-tolerant cultivars.

\section{Conflict of Interest}

The authors state that they have no conflict of interest.

\section{Author Contributions}

The experiment conducted, Ashutosh Srivastava; Formal analysis, Ashutosh Srivastava; Investigation, Ashutosh Srivastava and Puja Srivastava; Resources, Mayank Gururani; Supervision \& Validation, Puja Srivastava and RS Sarlach; Writing - original draft, Ashutosh Srivastava; Writing - review \& editing, Mayank Gururani.

\section{References}

Alyammahi O, Gururani, MA (2020) Chlorophyll-a Fluorescence Analysis Reveals Differential Response of Photosynthetic Machinery in Melatonin-Treated Oat Plants Exposed to Osmotic Stress. Agronomy10(10): 1520.
Bala S, Asthir B, Bains NS (2014) High temperature response leads to altered membrane permeability in conjunction with carbon utilization in wheat. Seed Science and Biotechnology 4: 10-14.

Bányai J, Kiss T, Gizaw SA, Mayer M, Spitkó T, Tóth V, Kuti C, Mészáros K, Láng L, Karsai I, Vida G (2020) Identification of superior spring durum wheat genotypes under irrigated and rain fed conditions. Cereal Research Communications 48:355-364.

Bishwas KC, Mukti RP, Dipendra R (2021) AMMI and GGE biplot analysis of yield of different elite wheat line under terminal heat stress and irrigated environments. Heliyon-Cell Press 7: $\mathrm{e} 07206$.

Božović D, Popović V, Rajicić V, Kostić M, Filipović V, Kolarić L, Ugranovic V, Spalević V (2020) Stability of the expression of the maize productivity parameters by AMMI models and GGEbiplot analysis. Notulae Botanicae Horti Agrobotanici Cluj-Napoca 48(3): 1387-1397.

Chowdhury MK, Hasan MA, Bahadur MM, Islam MR, Hakim MA, Iqbal MA, Javed T, Raza A, Shabbir R, Sorour S, Elsanafawy NE (2021) Evaluation of Drought Tolerance of Some Wheat (Triticum aestivum L.) Genotypes through Phenology, Growth, and Physiological Indices. Agronomy 11: 1792.

Egesi CN, Ilona P, Ogbe FO, Akoroda M, Dixon A (2007) Genetic variation and genotype $\mathrm{X}$ environment interaction for yield and other agronomic traits in cassava in Nigeria. Agronomy Journal 99: $1137-1142$

Fernández-Aparicio M, Flores F, Rubiales D (2009) Field response of Lathyrus cicera germplasm to crenate broomrape (Orobanche crenata). Field Crop Research 113: 321-327.

Gupta PK, Balyan HS, Sharma S, Kumar R (2020) Genetics of yield, abiotic stress tolerance and biofortification in wheat (Triticum aestivum L.). Theoretical and Applied Genetics 133(5): 1569-1602.

Gururani MA, Venkatesh J, Tran LSP (2015) Regulation of photosynthesis during abiotic stress-induced photoinhibition. Molecular Plant 8:1304-1320.

Jha UC, Bohra A, Nayyar H (2020) Advances in "omics" approaches to tackle drought stress in grain legumes. Plant Breeding 139(1): 1-27.

Kappachery S, Sasi S, Alyammahi O, Alyassi A, Venkatesh J, Gururani MA (2021). Overexpression of cytoplasmic Solanum tuberosum Glyceraldehyde 3-phosphate dehydrogenase (GAPDH) gene improves PSII efficiency and alleviates salinity stress in Arabidopsis. Journal of Plant Interactions 16(1): 398-410. 
Katuuramu DN, Luyima GB, Nkalubo ST, Wiesinger JA, Kelly JD, Cichy KA (2020) On-farm multi-location evaluation of genotype by environment interactions for seed yield and cooking time in common bean. Scientific reports 10(1): 1-12.

Kaya Y, Akçura M, Taner S (2006) GGE-Biplot analysis of multienvironment yield trials in bread wheat. Turkish Journal of Agriculture and Forestry 30:325-337.

Kumar A (2015) Association of Physio-biochemical traits with drought tolerance in a recombinant inbred population of Wheat. $\mathrm{Ph}$. D. Thesis submitted to Punjab Agricultural University, Luhdiana, India. Pp. 31-33

Kumar S, Sehgal SK, Kumar U, Prasad PVV, Joshi AK, Gill BS (2012) Genomic characterization of drought tolerance-related traits in spring wheat. Euphytica 186:265-276.

Mwiinga B, Sibiya J, Kondwakwenda A, Musvosvi C, Chigeza G (2020) Genotype x environment interaction analysis of soybean (Glycine max L.) Merrill) grain yield across production environments in Southern Africa. Field Crops Research 256: 107922.

Peterson DM, Wesenberg DM, Burrup DE, Erickson CA (2005) Relationships among agronomic traits and grain composition in oat genotypes grown in different environments. Crop Science 45: $1249-1255$.

Ranjith P, Rao MS (2021) Breeding for Drought Resistance. In Plant Breeding-Current and Future Views. Intech Open.

Srivastava A, Srivastava P, Khobra R, Sharma A, Sarlach R, Dogra A, Bains N (2016) Association of morpho-physiological traits in recombinant inbred population of wheat under rainfed environments. Indian Journal of Ecology 43 (Special Issue): 72-77.

Srivastava A, Srivastava P, Sharma A, Sarlach RS, Bains NS (2017) Effect of stem reserve mobilization on grain filling under drought stress conditions in recombinant inbred population of wheat. Journal of Applied and Natural Science 9(1): 1-5.

Tian R, Yang Y, Chen M (2020) Genome-wide survey of the amino acid transporter gene family in wheat (Triticum aestivum
L.): Identification, expression analysis and response to abiotic stress. International Journal of Biological Macromolecules 162: 1372-1387.

Wang X, Mao Z, Zhang J, Hemat M, Huang M, Cai J, Jiang D (2019) Osmolyte accumulation plays important roles in the drought priming induced tolerance to postanthesis drought stress in winter wheat (Triticum aestivum L.). Environmental and Experimental Botany 166: 103804.

Yaduvanshi A, Srivastava PK, Pandey AC (2015) Integrating TRMM and MODIS satellite with socio-economic vulnerability for monitoring drought risk over a tropical region of India.Physics and Chemistry of the Earth 83-84:14-27.

Yan W (2001) GGEbiplot - A windows application for graphical analysis of multienvironment trial data and other types of two-way data. Agronomy Journa193: 1111-1118.

Yan W (2002) Singular-value partitioning in biplot analysis of multienvironment trial data. Agronomy Journal 94: 990-996.

Yan W, Frégeau-Reid J (2008) Breeding line selection based on multiple traits. Crop Science 48: 417-423.

Yan W, Hunt LA, Sheng Q, Szlavnics Z (2000) Cultivar evaluation and mega-environment investigation based on the GGE biplot. Crop Science 40:597-605.

Yan W, Kang MS (2002) GGE biplot analysis: A graphical tool for breeders, geneticists, and agronomists, CRC Press, Boca Raton, FL.109-140.

Yan W, Rajcan I (2002) Biplot analysis of test sites and trait relations of soybean in Ontario. Crop Science 42:11-20.

Yan W, Tinker NA (2005) An integrated biplot analysis system for displaying, interpreting, and exploring genotype $\mathrm{x}$ environment interaction. Crop Science 45: 1004-1016.

Yan W, Tinker NA (2006) Biplot analysis of multi-environment trial data: Principles and applications. Canadian Journal of Plant Science 86: 623-645. 